\section{The Compass Model to plan faculty development programs}

\author{
Mohamed Mostafa Al-Eraky, 1,2 \\ Michelle McLean ${ }^{3}$
}

'University of Dammam, Saudi Arabia; ${ }^{2}$ Faculty of Medicine, Zagazig University, Egypt; ${ }^{3}$ Faculty of Health Sciences and Medicine, Bond University, Australia

\section{Abstract}

Faculty development is an imperative if institutions are to develop professional and competent teachers, educators, researchers and leaders. Planning of faculty development currently focuses on meeting the perceived needs of staff and their interests. We would like to propose the Compass Model as a conceptual framework to plan faculty development, which was inspired by the interplay between intrinsic and extrinsic forces for learning, as outlined in the Self-Determination Theory (SDT). In planning faculty development, the Compass Model acknowledges four agendas (directions) from various stakeholders: Strategies (N), Competencies (E), Resources (S) and Wish lists (W). The model then describes four avenues for faculty development offerings (quadrants): Foundation (NE), Innovation (SE), Response (SW) and Motivation (NW) (i.e. outputs, activities). The model was compared theoretically with another approach to faculty development planning. It was then piloted as a quality measure for a current program to check for omissions or missed opportunities. We plan to use it in a multi-center study to compare approaches in faculty development planning in different contexts. We hope our model assists faculty developers to consider all stakeholders' agendas when planning faculty development, beyond the current standard customer-based approach .

\section{Introduction}

Faculty development refers to the broad range of activities that institutions use to renew or assist faculty in their academic roles. ${ }^{1}$ Harden and colleagues ${ }^{2}$ have argued that the teacher is more than a lecturer, listing at least 11 additional roles. The expectations of today's academics now include clinical, college and university service, ${ }^{3}$ as well as leadership and scholarly activities. ${ }^{4}$ As most academics are ill-prepared for many of their new duties, faculty development is an imperative rather than a luxury if institutions are to develop pro- fessional and competent teachers, educators, researchers and leaders. ${ }^{5}$ While much has been written about faculty development, the planning stage of this important practice has been somewhat neglected.

We would like to propose the Compass Model as a conceptual framework to plan faculty development. The notion of the compass has been used to highlight directions in research, ${ }^{6}$ particularly in medical education research, ${ }^{7}$ in marketing ${ }^{8,9}$ and in psychology and spirituality. ${ }^{10}$ Williamson and Blackburn ${ }^{11}$ used the COMPASS acronym for an approach to leadership, while others have used the compass as a mind-tool to set priorities (i.e. True North), in bioethics ${ }^{12-14}$ and professionalism in social networking. ${ }^{15} \mathrm{~A}$ famous compass in higher education explained the interrelated processes and dynamics of Process Education with respect to five areas for developing the individual and the institution. ${ }^{16}$

Faculty development represents an investment in human capital, but it is all too frequently planned using a survey of faculty members only, catering for their preferences. We argue that these so-called needs assessments are no more than wish lists. In this regard, our Compass Model is unique in that it considers the agendas of various stakeholders when planning faculty development. It also provides suggestions in terms of faculty development activities.

\section{Innovation}

The theoretical underpinning of our Compass Model was inspired by the SelfDetermination Theory (SDT), ${ }^{17}$ which describes the interplay between intrinsic and extrinsic factors in learning. According to the SDT, when planning faculty development, two types of input should be considered: autonomous (intrinsic) and controlled (extrinsic). The autonomous input is represented by the horizontal axis of the Compass Model and reflects the individual competencies of academics (East) and their areas of interests (West). The controlled drive lies on the vertical axis and represents the institutional strategies (North) and available resources (South). The Compass Model therefore addresses Bland and Simpson's ${ }^{18}$ call for faculty development to link individual and organizational needs and pair organizational development with individual skill development. ${ }^{19}$

The Compass Model (Figure 1) comprises the four primary directions $(\mathrm{N}, \mathrm{E}, \mathrm{W}, \mathrm{S})$ and four quadrants in-between (NW, NE, SW, SE). Directions represent the four perspectives (input) of the various stakeholders. Faculty developers are expected to gather NEWS (an acronym for directions) when planning faculty
Correspondence: Mohamed M.Al-Eraky, Medical Education Unit, University of Dammam, P.0. Box 40344, Al-Khobar 31952, Saudi Arabia Tel. +966.546.775.005.

E-mail: maleraky@ud.edu.sa

Key words: compass model, faculty development.

Conflict of interest: the authors report no conflicts of interest.

Received for publication: 29 September 2011. Revision received: 2 April 2012.

Accepted for publication: 13 April 2012.

This work is licensed under a Creative Commons Attribution NonCommercial 3.0 License (CC BYNC 3.0).

(C) Copyright M.M. Al-Eraky and M. McLean, 2012 Licensee PAGEPress srl, Italy

Medical Education Development 2012; 2:e4 doi:10.4081/med.2012.e4

development. $N$ the strategies, is influenced by the institutional mission and vision as well as the requirements of accreditation bodies. $E$ acknowledges the core competencies required for individual academics. $W$ denotes the interest areas of individual faculty members, while $S$ concedes that resources may be limited. Directions therefore attend to the four basic questions in terms of what faculty developers should (N) vs. could (S) offer and what faculty members want $(\mathrm{W})$ vs. require $(\mathrm{E})$.

The Compass also has four quadrants, acknowledging the potential offerings and activities in faculty development programs (output). Some initiatives are necessary to meet standards (Foundation). When resources may be limited, innovation is required to meet current and evolving faculty development requirements (Innovation). The Response quadrant is the most flexible section of the plan, in which ad hoc offerings are organized to cater for the expectations of faculty members using available resources. In the Motivation quadrant, the institution offers and supports faculty members in terms of scholarships and sabbaticals and long-term career development to empower them to professionalize their practice as educators, researchers and leaders. Activities in this quadrant add considerable value to the institution's teaching and learning, research and administration quality. Further elaboration of each direction and quadrant can be found in Figure 2, ${ }^{20-35}$ which draws on reported trends and best practices in faculty development.

Unlike Kolb's experiential learning model, ${ }^{36}$ there is no sequential relationship between directions or quadrants in our model and should therefore not be viewed as a cycle. Directions and quadrants of our Compass 
Model are not measures or scales. Each direction represents a standalone resource for data (input) to plan faculty development, while each quadrant suggests a separate avenue for implementation (output), taking cognizance of the input from two directions.

\section{Evaluation of the Model}

The Compass Model can be evaluated in two ways: theoretically, by comparing the model with other approaches for planning faculty development and practically, by using the model to scrutinize a faculty development program as a case study.

Theoretical comparative analysis

Table 1 compares the Compass Model with the Kern's six-step approach to curriculum development. ${ }^{37}$

Step (1) can be compared with the True North of the Compass, either internally by the institution's leadership or by an external accrediting, certifying or professional entity,

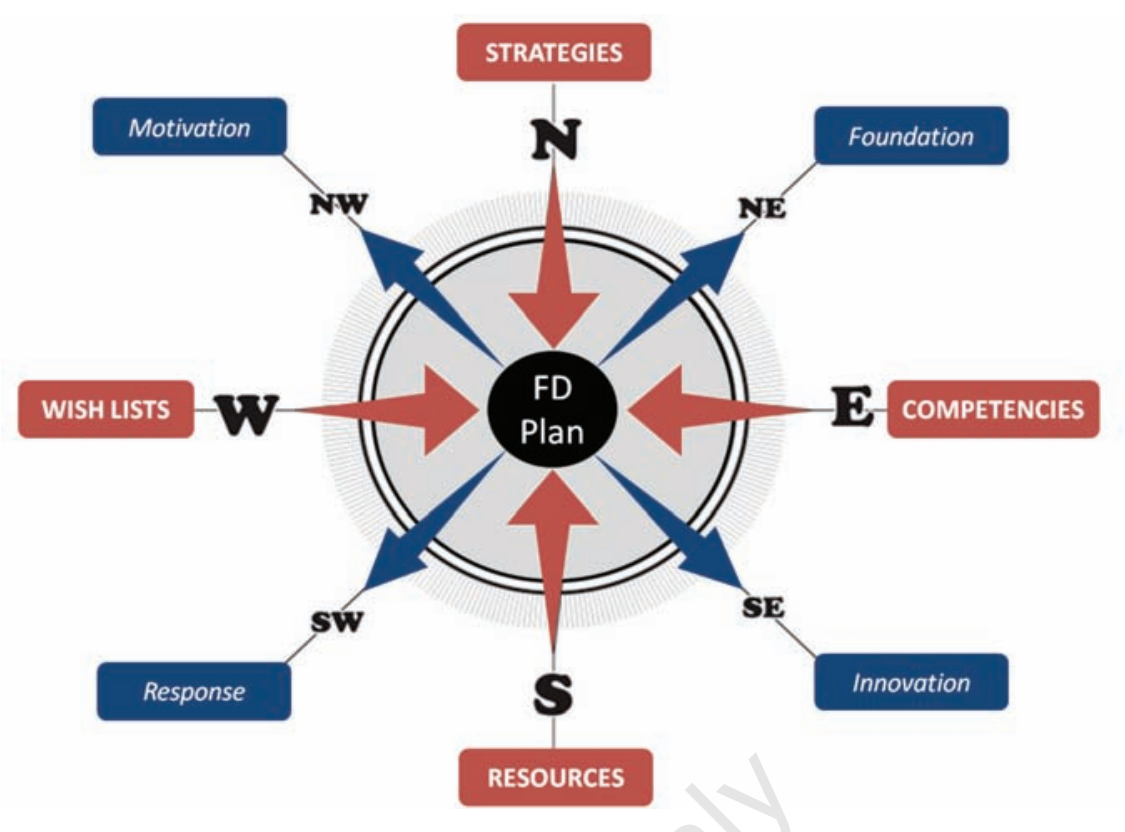

Figure 1.The Compass Model for planning faculty development. Four directions (N, E, W, S) represent the major input from different stakeholders (input for planning) and four quadrants (NE, SE, SW, NW) represent areas for activities or faculty development initiatives, approaches and programs (output or offerings).

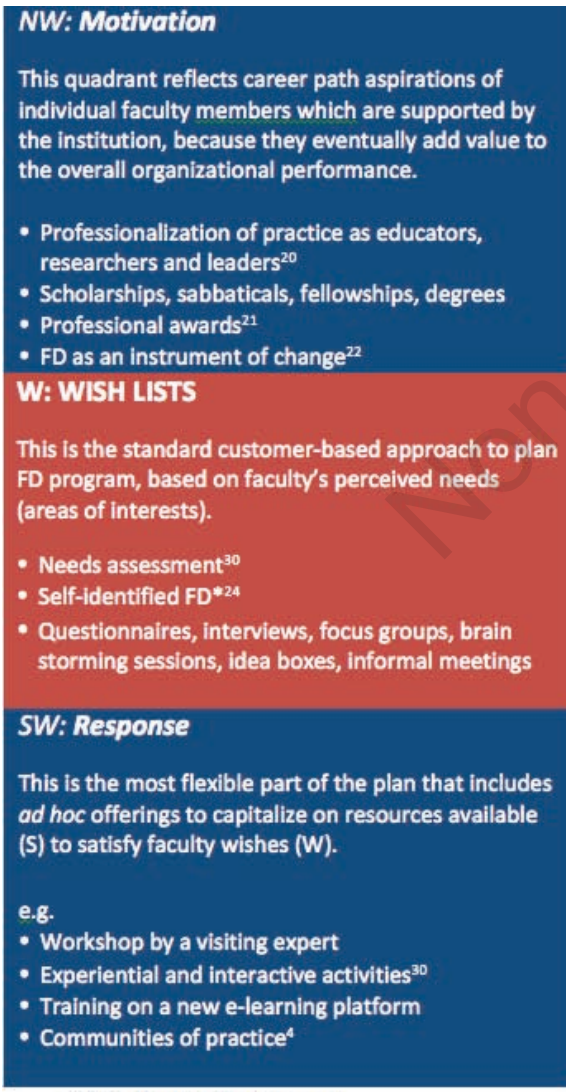

\section{N: STRATEGIES \\ Standards policies dictate FD*. They are decided by the institutional leadership or by \\ accrediting/certifying/professional bodies. \\ - Educational strategies ${ }^{23}$ \\ - Institutional environment ${ }^{24}$ \\ - Certifying and professional bodies \\ - Social accountability ${ }^{25}$ \\ - Global standards ${ }^{26}$}

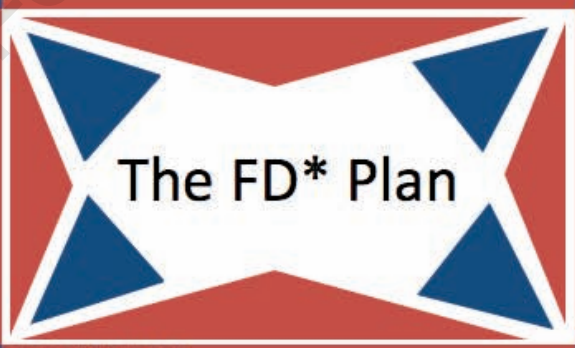

\section{S: RESOURCES}

\section{These resources include}

- Budget

- Number and expertise of educators

- Protected time for professional development

- Venues available for training

- Context of practice; outpatient, inpatient or ambulatory.

- Infrastructure, including technology

- Distribution of campuses

- Networks and collaborations

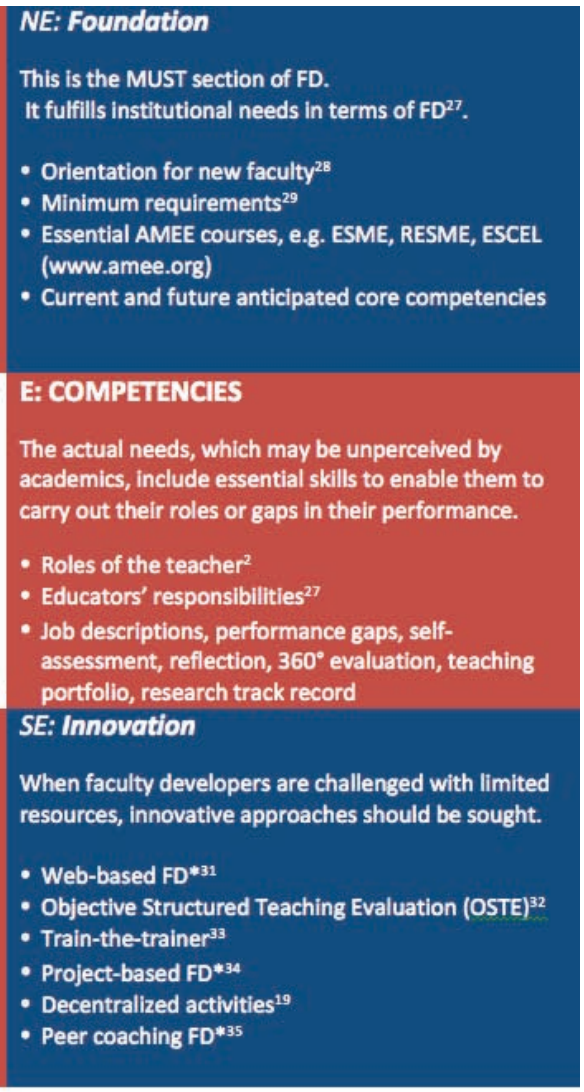

*FD: Faculty Development

Figure 2. Best practices and trends in faculty development from the literature are plotted in different directions (input from N, E, W, S) and quadrants (output in NE, SE, SW, NW) of the Compass Model. Red boxes are input to the plan and while the blue one are its output. 
i.e. the problem is identified against standards. Step (2) equates with the horizontal axis of our Compass Model, i.e. the wishes of the faculty members (West) and their actual needs to perform their duties (East). Any plan is evaluated by its effectiveness to achieve its objectives. Steps (3) and (4) are defined in light of strategies (North) and resources (South). Kern' steps 1-4 can be viewed as inputs (directions) in the Compass Model. Step (5) corresponds with the offerings of the program, which is elaborated and addressed in the four quadrants of the Compass. We believe that our model can be used as a quality check to specifically to address a neglected area of FD planning and implementation. It is therefore a tool for evaluation and feedback, i.e. Kern's last step.

Faculty developers may use other models or frameworks to ensure appropriate implementation and for measuring the impact of faculty development. To this end, Bland and colleagues $^{38}$ consider the impact of faculty development at three levels: individual, institution and leadership, while Kirkpatrick' ${ }^{39}$ model considers four levels of impact, which escalate from participant reaction to a change in institutional culture.

\section{Practical testing}

The Compass Model was piloted at two colleges to check for neglected agendas (directions) or missed opportunities (quadrants) during the planning stage of faculty development. Interviews were conducted with faculty development program coordinators to learn about their approaches in planning and execution of faculty development workshops or courses. We used two open-ended questions; (1) Describe how do you plan for your faculty development event or program? (2) Describe how you then decide to deliver the event or course? Both coordinators reported relying mainly on undertaking a faculty needs assessment survey to set priorities for themes and topics for the next semester. They did not report evaluating actual competencies or performance gaps, as they are not involved in the process of appraisal or promotion. We interpret this as an emphasis on the perceived needs (wish lists) of candidates (West), without attending to their actual or unperceived needs (East). Thus, in terms of the Compass Model, the input for these coordinators is largely in a West direction, i.e. surveys of and feedback from academics, which is more easily obtained and openly communicated, compared with input from the East (competencies and possible deficiencies). This finding was not surprising as this is the current standard practice in faculty development planning. Evaluating competencies and performance gaps is a far more daunting task as it relies on clear expectations of the roles of academics and requires tools to measure performance against expectations,

Table 1. Kern's (2009) six-step approach to curriculum development ${ }^{37}$ mapped against the Compass Model.

\begin{tabular}{ll} 
Kern's (2009) six-step approach & Compass model \\
Step 1: Problem identification and general needs assessment & North direction \\
Step 2: Targeted needs assessment & East and West directions \\
\hline Step 3: Goals and objectives & North and South directions \\
Step 4: Educational strategies & North direction \\
\hline Step 5: Implementation & All four quadrants \\
Step 6: Evaluation and feedback & All directions and quadrants \\
\hline
\end{tabular}

e.g. 360 degree evaluation, research recordtracking in terms of scholarly activities, peer assessment, reflection and assessment of teaching portfolios.

The program coordinators also expressed concern over the absence of a documented institutional strategy for faculty development, i.e. the Northern input was not recognized in both institutions. Likewise, input from the South was generally not considered due to ambiguity of resource availability, particularly in the absence of protected time for development and the vague criteria for applying for scholarships and sabbaticals. From the interviews, it emerged that faculty development offerings from the two faculty developers canvassed were mainly in the Response quadrants, i.e. workshops on topics recommended by faculty members, within the available budget, time frame and expertise of local and visiting educators. In both instances, their programs were a collection of ad hoc activities, with little attention afforded to the $\mathrm{N}$ and $\mathrm{E}$ directions. The Foundation, Motivation and Innovation quadrants were thus neglected.

\section{Future plans}

We plan to determine empirically whether the Compass Model can inform faculty developers to review and improve their practice when planning faculty development programs. A survey has been drafted (Supplementary Table 1) to be used in a multi-center survey with two main objectives: i) to test the Model as a quality measure and evaluate its effectiveness in improving faculty development planning, and, ii) to compare approaches to faculty development planning in different contexts.

\section{Conclusions}

The Compass Model takes into account input from four directions, all of which can impact on planning, and offers suggestions for implementation in four quadrants. A well planned faculty development program should offer activities in all quadrants. Faculty developers can use our Compass Model to plan their faculty development, to check for omissions and neglected input areas (directions) in order not to miss out on opportunities as they arise (quadrants). We hope our Model will help faculty developers to acknowledge other inputs beyond the standard customer-based approach to planning, which services the personal selfperceived needs of individual faculty members only. The Compass Model can be used to improve faculty development practice and make an informed decision in terms of meeting the institutional mission and vision, i.e. true North.

\section{References}

1. Centra JA. Types of faculty development programs. Journal of Higher Education 1978;49:151-62.

2. Harden RM, Crosby J. AMEE education guide no. 20: The good teacher is more than a lecturer: The twelve roles of the teacher. Med Teach 2000;22:334-47.

3. Bligh J, Brice J. Further insights into the roles of the medical educator. Acad Med 2009;84:1161-5.

4. Steinert Y. Commentary: faculty development: the road less traveled. Acad Med 2011;86:409-11.

5. McLean M, Cilliers F, van Wyk JM. AMEE guide 36 . Faculty development: Yesterday, today and tomorrow. Med Teach 2008;30: $555-84$.

6. Burns J. Research agendas: when the roadmap lacks a compass, we are all lost. Crit Care Med 2012;40:345-6.

7. Ringsted C, Hodges B, Scherpbier A. The research compass: an introduction to research in medical education: AMEE Guide no. 56. Med Teach 2011;33:695-709.

8. Hines JD, Murray M. A compass for customer needs. Hosp Mater Manage Q 1998; 19:50-5.

9. Wharf Higgins J. Navigating through translational research: a social marketing compass. Health Mark Q 2011;28:1-15.

10. Montgomery D, Montgomery K. 2012. The compass model of personality. Available from: http://www.compasstherapy.com/ CompassModelPersonality.html. Accessed 
on on 21 February 2012.

11. Williamson R, Blackburn B. Rigorous schools and classrooms: leading the way. Available from: http:/www.ronwilliamson. com/RW_Web/NCMSA_2011_files/Rigorou sSchools.pdf. Accessed on 21 February 2012.

12. Lindsay RA. Bioethics policies and the compass of common morality. Theor Med Bioeth 2009;30:31-43.

13. Meru M. Following your moral compass: ethics in dental school. J Am Coll Dent 2010;77:4-9.

14. Pellegrino ED. Medical ethics in an era of bioethics: resetting the medical profession's compass. Theor Med Bioeth 2012; 33:21-4.

15. Landman MP, Shelton J, Kauffmann RM, Dattilo JB. Guidelines for maintaining a professional compass in the era of social networking. J Surg Educ 2010;67:381-6.

16. Burke K, Lawrence B, El-Sayed M, Apple D. 2009 Process education: past, present and future. Available from: http://www.pcrest2. com/institute_resources/TI/pe.htm. Accessed on 25 February 2012.

17. Williams GC, Saizow RB, Ryan RM. The importance of self-determination theory for medical education. Acad Med 1999;74: 992-5.

18. Bland CJ, Simpson D. Future faculty development in family medicine. Fam Med 1997;29:290-3.

19. Baxley EG, Probst JC, Schell BJ, et al. Program-centered education: a new model for faculty development. Teach Learn Med 1999;11:94-9.

20. McLean M. How to professionalise your practice as a health professions educator. Med Tech 2010;32:953-5.

21. Schofield SJ, Bradley S, Macrae C, et al. How we encourage faculty development. Med Tech 2010;32:883-6.

22. Steinert Y, Cruess RL, Cruess SR, et al. Faculty development as an instrument of change: a case study on teaching professionalism. Acad Med 2007;82:1057-64.

23. Harden RM, Sowden S, Dunn WR. Educational strategies in curriculum development: the SPICES model. Med Educ 1984; 18:284-97.

24. Hitchcock MA, Stritter FT, Bland CJ. Faculty development in the health professions: conclusions and recommendations. Med Teach 1993;14:295-309.

25. Woollard RF. Caring for a common future: medical schools' social accountability. Med Educ 2006;40:301-13.

26. McKimm J, McLean M. Developing a global health practitioner: time to act? Med Teach 2011;33:626-31.

27. Simpson D, Marcdante K, Morzinski J, et al. Medical education fellowships - fifteen years of aligning faculty development with primary care clinician-educator roles and academic advancement at the Medical College of Wisconsin. Acad Med 2006;81: 945-53.

28. Wilkerson L, Irby DM. Strategies for improving teaching practices: a comprehensive approach to faculty development. Acad Med 1998;73:387-96.

29. Stern DT, Wojtczak A, Schwarz MR. The assessment of global minimum essential requirements in medical education. Med Teach 2003;25:589-95.
30. Steinert Y, Mann K, Centeno A, et al. A systematic review of faculty development initiatives designed to improve teaching effectiveness in medical education: BEME Guide No. 8. Med Teach 2006;28:497-526.

31. McKimm J, Swanwick T. Web-based faculty development: e-learning for clinical teachers in the London Deanery. Clin Teach 2010;7:58-62.

32. Wamsley MA, Julian KA, Vener MH, Morrison EH. Using an objective structured teaching evaluation for faculty development. Med Educ 2005;39:1160-1.

33. Skeff KM, Stratos GA, Berman J, Bergen MR. Improving clinical teaching. Evaluation of a national dissemination program. Arch Intern Med 1992;52:1156-61.

34. Gusic ME, Milner RJ, Tisdell EJ, et al. The essential value of projects in faculty development. Acad Med 2010;85:1484-91.

35. McLeod PJ, Steinert Y. Peer coaching as an approach to faculty development. Med Teach 2009;31:1043-4.

36. Kolb D, Frye R. Toward an applied theory of experiential learning. Theories of group process. London: John Wiley, 1975.

37. Kern DE, Thomas PA, Howard DM, Bass EB. Curriculum development for medical education: a six-step approach. 2nd ed. Baltimore: Johns Hopkins University Press; 2009.

38. Bland CJ, Seaquist E, Pacala JT, et al. One school's strategy to assess and improve the vitality of its faculty. Acad Med 2002;77: 368-76.

39. Kirkpatrick DL. Evaluating training programs: the four levels. San Francisco: Berrett-Koehler Publishers; 1994. 